\title{
Patient-perceived barriers and enablers to adherence to physiotherapist prescribed self-management strategies
}

Kerry Peek BSC (Hons), PhD

Lecturer, School of Medicine and Public Health, University of Newcastle, University Drive, Callaghan, NSW. Australia

Mariko Carey DPsych

Senior Research Fellow, Health Behaviour Research Group, School of Medicine and Public Health, University of Newcastle, University Drive, Callaghan, NSW. Australia

Lisa Mackenzie $P h D$

Post-doctoral Research Fellow, Health Behaviour Research Group, School of Medicine and Public Health, University of Newcastle, University Drive, Callaghan, NSW. Australia

Robert Sanson-Fisher PhD

Director (Health Behaviour Research Group), Health Behaviour Research Group, School of Medicine and Public Health, University of Newcastle, University Drive, Callaghan, NSW. Australia

\section{ABSTRACT}

The objectives of this study were to describe patient-reported adherence to physiotherapist-prescribed self-management strategies; and the perceived barriers and enablers to adherence to each strategy. Patients attending physiotherapy private practices ( $n=4)$ were observed during their consultation. Patients prescribed one or more self-management strategies received a follow-up telephone interview within 10-14 days of the observed consultation and were asked to self-report their level of adherence and their perceived barriers and/or enablers to each prescribed strategy. Results indicated that patients $(n=108)$ reported receiving 177 strategies and being fully adherent to $36 \%$ (95\% Cl: $29-44 \%)$ of these strategies. Patient-reported adherence barriers $(n=113)$ and enablers $(n=172)$ were coded using a modified version of the World Health Organisation five dimensions of adherence. Frequently reported barriers included social/economic-related $(n=52 ; 46 \%)$ such as being too busy, and patient-related ( $n=29 ; 26 \%)$ including being too tired/lack of motivation. Frequently reported enablers included therapy-related $(n=71 ; 41 \%)$ such as "the strategy was easy to complete", and condition-related ( $n=45 ; 26 \%$ ) including "that the strategy helped to manage symptoms". Thus, patient adherence may be aided by ensuring that: the strategy is less complex; it does not cause pain; it isn't time consuming; and it leads to an improvement in condition-related symptoms.

\section{Peek, K., Carey, M., Mackenzie, L., Sanson-Fisher, R. (2018). Patient-perceived barriers and enablers to adherence to physiotherapist prescribed self-management strategies. New Zealand Journal of Physiotherapy 46(3): 105-112. doi:10.15619/NZJP/46.3.03}

Key Words: Physiotherapy, Compliance, Self-care, Exercise, Advice.

\section{INTRODUCTION}

Physiotherapist-prescribed self-management strategies refer to specific actions given to the patient for them to implement at home (away from the supervised environment) in order to manage their condition. Strategies may include the prescription of an exercise programme, advice to complete a functional activity (such as walking) or to refrain from a specific activity (such as playing basketball), the use of a brace, and non-pharmacological pain interventions such as ice or heat (Liddle, Baxter, \& Gracey, 2009; Page, Hinman, \& Bennell, 2011; Peek, Sanson-Fisher, Mackenzie, \& Carey, 2015, 2016). Physiotherapist-prescribed self-management strategies have been shown to be as effective as physiotherapist provided treatment resulting in potential cost savings for both the patient and the health care system (Novak, 2011) as well as increasing the flexibility of treatment options. Successful self-management requires a partnership in which the physiotherapist supports the patient to take responsibility for the management of their symptoms at home, away from the physiotherapy clinic (Matthews et al., 2015).

The effectiveness of evidence-based self-management strategies has reportedly been related to patient adherence (Kolt \& McEvoy, 2003; Peek, Sanson-Fisher, Mackenzie, \& Carey 2015, 2016). A systematic review on adherence to therapeutic splint wear in adults with acute upper limb injuries reported that poor adherence to splinting can lead to worse outcomes for the patient such as delayed recovery or increased risk of surgical intervention (O'Brien, 2010). Similarly, a randomised controlled trial of 150 patients with hip and/or knee osteoarthritis reported that adherence to recommended home exercises and being more physically active were significantly associated with better patient outcomes related to pain and function (Pisters, Veenhof, Schellevis, et al., 2010). However, rates of adherence to physiotherapist-prescribed self-management strategies have ranged from $44-56 \%$ of patients completing a homebased pelvic floor exercise programme every day (Sacomori, 
Berghmans, Mesters, de Bie, \& Cardoso, 2015) to 70-78\% of patients with hip and/or knee osteoarthritis completing a home exercise and walking programme (Pisters, Veenhof, de Bakker, Schellevis, \& Dekker, 2010).

Patient adherence has been reported as a multidimensional phenomenon determined by the interplay of five factors, which have been termed by the World Health Organisation (WHO) as the five dimensions of adherence (Sabaté, 2003). These five dimensions, which include social/economic-related, conditionrelated, therapy-related, healthcare team and system-related, and patient-related factors, aim to dispel the belief that patients are solely responsible for following prescribed self-management strategies (examples of the five dimensions are included in Figure 1). They also reflect an understanding of how multiple factors can influence a patient's behaviour and their capacity to adhere to treatment (Sabaté, 2003). Barriers to patient adherence to home-based exercise for patients with musculoskeletal conditions reported in a systematic review included the presence of pain, low self-efficacy, depression, anxiety, and poor social support (Jack, McLean, Moffett, \& Gardiner, 2010). However, it has been reported that some patients demonstrate an ongoing commitment to their self-managed exercise programme in spite of these barriers (Robinson, Newton, Jones, \& Dawson, 2014), and that on the whole, patients want to adhere but that they often have difficulty integrating the required behaviours into their daily routines (Bassett, 2015).

Enhancing physiotherapists' understanding of patient-perceived barriers and enablers to adherence may assist physiotherapists and their patients in developing collaborative self-management treatment plans in which these barriers may be better managed. For example, patients may be more likely to adhere to selfmanaged strategies which are easier and more convenient to complete (DiMatteo, Haskard-Zolnierek, \& Martin, 2012) such as one simple exercise versus ten more complex ones; or a strategy prescribed to provide pain relief such as the use of heat or ice (French, Cameron, Walker, Reggars, \& Esterman, 2006). One qualitative study cited the most common enablers to adherence to a regular self-managed exercise programme as: an established daily structure that incorporated exercise, anticipated positive feelings associated with exercise, and accountability to others (McArthur, Dumas, Woodend, Beach, \& Stacey, 2014). However, the majority of studies which have reported barriers to patient adherence to self-management strategies prescribed by physiotherapists have related to exercise only (Campbell et al., 2001; Lui \& Hui, 2009; McArthur et al., 2014). If physiotherapists can understand the nature of patient reported barriers and enablers to self-management more generally, this may inform clinical decision-making to promote long-term patient adherence, which may ultimately improve patient treatment outcomes to a range of home-based strategies.

The objectives of this study were to describe patient-reported levels of adherence to physiotherapist-prescribed selfmanagement strategies; and patient-perceived barriers and enablers to adherence to each prescribed strategy.

\section{METHODS}

\section{Study Design}

A cross-sectional study design was utilised whereby patients, who were observed (by a research physiotherapist) to receive at least one self-management strategy prescribed by their physiotherapist, were later contacted to complete a telephone interview. During the interview participants were asked to name each strategy that was prescribed to them during the observed consultation, self-report their level of adherence to each strategy and describe their reasons for this level of adherence. Ethics approval for this research project was granted through the University of Newcastle (Australia), Human Research Ethics Committee (no: H-2015-0030). Data were collected between May and October 2015.

\section{Setting}

This study was undertaken in four physiotherapy private practices in Australia (two in South Australia and two in New South Wales).

\section{Participants}

Physiotherapists: Practising physiotherapists were recruited via the website of the peak professional organisation which represents the interests of physiotherapists within Australia: Australian Physiotherapy Association (available at: http://www. physiotherapy.asn.au/apawcm/controls/findaphysio.aspx.). This method of recruitment has been used in previous research as an alternative approach now that accessing mailing lists through the Physiotherapy Board of Australia (national registration authority) is no longer permitted (Peek, Carey, Sanson-Fisher, \& Mackenzie, 2017). Physiotherapists listed within $50 \mathrm{~km}$ radius of two large cities were emailed an initial invitation to discuss participation in this study. Physiotherapists were invited to contact the research team to arrange a face-to-face meeting with the study's primary researcher (a physiotherapist with 18 years of clinical experience). The face-to-face meeting provided an opportunity to further discuss study participation and to gain consent from the physiotherapist and practice manager/owner. Additional physiotherapists employed within each practice were also invited to attend this meeting and were provided with the opportunity to participate. Physiotherapists were eligible to participate if they worked in private practice and saw a general case mix of adult patients.

Patients: Eligible patients included those: aged 18 years and older, physically and mentally able to give informed consent, and who had sufficient English proficiency to complete a telephone interview.

A consecutive sample of patients were approached by the study's primary researcher prior to their attendance for an initial or follow-up consultation with a participating physiotherapist. Written and verbal information was provided to potential patient participants regarding the study's aims and methods before requesting written consent to participate. Patients were also asked to provide their telephone number and preferred contact time in order to complete a follow-up telephone interview with the same researcher within 10-14 days of the observed consultation. A consecutive sample of patients was recruited to try to minimise recruitment bias.

\section{Observational data collection}

The study's primary researcher observed one physiotherapistpatient consultation per consenting patient. An observation coding checklist was specifically designed, and pilot tested 
for this study by a team of physiotherapists and health behaviourists and was used to record the number and type of self-management strategies prescribed to each patient during the observed consultation as well as details related to the nature of the injury patients were attending for treatment. For this study, a self-management strategy included any strategy that the physiotherapist specifically gave to the patient to complete independently at home, such as exercise, a brace to wear or ice pack. Specific definitions for each self-management strategy were determined a priori. For example: exercise was only listed as a self-management strategy if the physiotherapist prescribed the patient with a specific movement action to complete at home such as squats, biceps curls or hamstring stretch. If the physiotherapist recommended physical activity such as swimming or walking this was included under advice. Education was considered to be an intervention to aid adherence rather than a self-management strategy and therefore was not recorded.

\section{Patient telephone interview}

The patient telephone interview was conducted within 10-14 days of the observed consultation. This timeframe was selected to hopefully allow the patient sufficient time to have practised each strategy more than once but not so long that the patient might have difficulty recalling the observed consultation. The telephone interview included demographic questions regarding the patient's age and gender.

Patients were then asked the following question:

1. 'Please tell me the name/s of any self-management strategy that you were given in the consultation that was observed by the researcher only' (open ended)

Next, patients were given a study definition of adherence:

'With regard to adherence:

- Complete adherence means that you completed all (100\%) of the strategy as given to you by your physiotherapist.
- Partial adherence means that you completed:

- Most (>50\%) of the strategy as given to you by your physiotherapist, or,

o Some $(<49 \%)$ of the strategy as given to you by your physiotherapist

- And non-adherence means that you did not do any (0\%) of the strategy as given to you by your physiotherapist in the observed consultation'

Patients were then asked:

2. 'Over the last seven days, can you tell me your level of adherence to <name of strategy as reported in question 1> (response options: all, most, some, none).

3. 'What are the main reasons that you gave this answer?' (Open ended).

Questions 2 and 3 were repeated for each strategy as reported by the patient in response to question 1 .

Data analysis

Data analysis was conducted using the statistical software package, Stata® 14 (Texas, USA). Descriptive statistics were used to describe physiotherapist and patient characteristics as well the number of patients prescribed with at least one selfmanagement strategy and patient-reported level of adherence.

A simplified quantitative content analysis, a social science methodology which focuses on patterns in the content of communication (Potter \& Levine-Donnerstein, 1999), was used to analyse the patient-perceived reasons for their self-reported level of adherence using a modified version of the WHO five dimensions of adherence (Sabaté, 2003). The WHO classified factors associated with adherence into five dimensions related to social/economic-related, condition-related, therapy-related, healthcare team and system-related, and patient-related which we have adapted using physiotherapy specific examples as shown in Figure 1. The WHO five dimensions of adherence

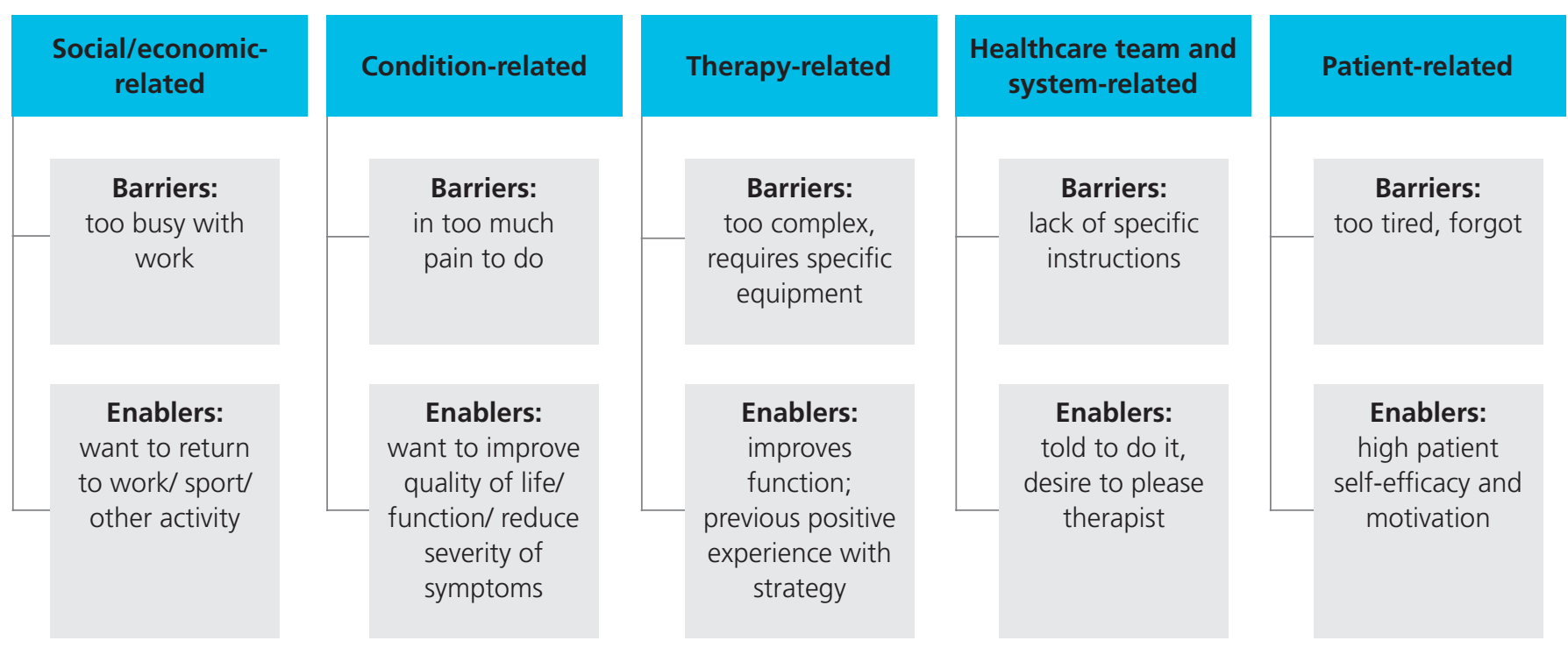

Figure 1: Modified version of the WHO five dimensions of adherence 
were used for coding in an attempt to standardise the factors associated with adherence. A coding guideline was developed whereby the definitions and coding criteria for each of the five dimensions of adherence was stated. Each patient-reported reason was first analysed and then single coded by the first author as to whether the reason was a barrier or enabler to adherence and then recorded against one of the five dimensions using a quantitative-coding sheet. Frequencies and percentages were calculated for reported barriers and enablers.

\section{RESULTS}

\section{Demographics}

Physiotherapists: From five emailed invitations, four physiotherapists contacted the study's primary researcher to schedule a face-to-face meeting. This led to the recruitment of 14 physiotherapists from four separate practices within South Australia $(n=6)$ and New South Wales $(n=8)$. Of these 14 physiotherapists, six (43\%) were male and 12 (86\%) received their physiotherapist qualification in Australia.

Patients: Of the 119 patients screened for eligibility, 114 eligible patients were approached to discuss participation (reasons for ineligibility included: insufficient English to be able to give consent $n=1$; younger than 18 years $n=4$ ). In total, 113 patients consented to be observed during their physiotherapy consultation (consent rate 99\%). Of the 113 observed physiotherapist-patient consultations, 108 patients were observed to receive at least one self-management strategy and were scheduled for telephone interview. The mean age of patient participants was 52 years (range 25-95). Of the 108 participants, 77 (68\%) were female. All patient participants attended for physiotherapy treatment of a musculoskeletal condition involving the upper limb $(n=21)$, spine $(n=82)$ or lower $\operatorname{limb}(n=10)$.

\section{Patient reported adherence to the physiotherapist- prescribed strategies.}

Patients ( $n=108$ ) reported being prescribed 177 selfmanagement strategies (mean $=1.64$ strategies per patient). Prescribed self-management strategies included exercise $(n=101)$, specific advice $(n=52)$, heat packs $(n=11)$, ice $(n=5)$, removable brace $(n=2)$, lumbar roll $(n=5)$ and self-taping $(n=1)$.
In total, patients reported being completely adherent to 64 strategies (36\% (95\% Cl: 29-44\%); mostly adherent to 62 strategies (35\% (95\% Cl: 28-43\%); somewhat adherent to 35 strategies (20\% (95\% Cl: $14-26 \%)$ and non-adherent to 16 strategies (9\% (95\% Cl: $2-9 \%$ ) in the seven days prior to the telephone interview. Table 1 shows the level of patient-reported adherence per type of prescribed strategy.

Patient-perceived barriers and enablers to adherence. For each self-management strategy patients were asked to report the main reasons for their reported level of adherence. This resulted in the coding of a total of 113 perceived barriers and 172 perceived enablers to adherence which were then coded using the modified five dimensions of adherence (Sabaté, 2003), Table 2.

The most frequently described dimension of adherence-barrier was social/economic related with being 'too busy' reported for 49 (43\%; 95\% Cl: 34-53\%) individual self-management strategies. Other frequently reported dimension-barriers were patient-related (too tired or lack of motivation), and conditionrelated (not doing the strategy when patients were in pain), Table 2.

The most frequently reported dimension of adherence-enabler was therapy-related with 'ease to complete the strategy' being commonly reported ( $n=54 ; 31 \% ; 95 \% \mathrm{Cl}: 25-38 \%$ ). Other frequently reported dimension-enablers were condition-related (the strategy helped manage long-term symptoms related to the patient's condition), and healthcare team and system-related (being told to complete the strategy by their physiotherapist), Table 2 .

\section{DISCUSSION}

Given the frequency of self-management strategy prescription in physiotherapy private practice, physiotherapists should consider the assessment of patient adherence to optimise the effectiveness of each home-based treatment strategy. In our study, $36 \%$ of strategies were self-reported as being completely adhered to, similar to percentages reported in earlier research (Alexandre, Nordin, Hiebert, \& Campello, 2002; Schneiders, Zusman, \& Singer, 1998). The percentage of each prescribed

\section{Table 1: Level of patient-reported adherence per type of prescribed self-management strategy}

\begin{tabular}{|c|c|c|c|c|}
\hline \multirow[t]{2}{*}{ Name of Self-Management Strategy } & \multicolumn{4}{|c|}{ Number (\%) of patients self-reporting each level of adherence per prescribed strategy } \\
\hline & All & Most & Some & None \\
\hline Exercise $(n=101)$ & $42(41 \%)$ & $27(27 \%)$ & $19(19 \%)$ & $13(13 \%)$ \\
\hline Advice $(n=52)$ & $6(12 \%)$ & $31(60 \%)$ & $15(29 \%)$ & 0 \\
\hline Heat $(n=11)$ & $6(55 \%)$ & $4(36 \%)$ & $1(9 \%)$ & 0 \\
\hline Ice $(n=5)$ & $1(20 \%)$ & $4(80 \%)$ & 0 & 0 \\
\hline Removable Brace $(n=2)$ & $2(100 \%)$ & 0 & 0 & 0 \\
\hline Lumbar roll $(n=5)$ & $2(40 \%)$ & 0 & 0 & $3(60 \%)$ \\
\hline Self-taping $(n=1)$ & $1(100 \%)$ & 0 & 0 & 0 \\
\hline
\end{tabular}


Table 2: Patient perceived barriers and enablers to adherence to physiotherapist-prescribed self-management strategies in the past seven days using the adapted WHO five dimensions of adherence.

\begin{tabular}{|c|c|c|c|c|c|}
\hline & $\begin{array}{l}\text { Social/economic- } \\
\text { related }\end{array}$ & Condition-related & Therapy-related & $\begin{array}{l}\text { Healthcare team } \\
\text { and system- } \\
\text { related }\end{array}$ & Patient-related \\
\hline $\begin{array}{l}\text { Barriers } \\
n=113\end{array}$ & $\begin{array}{l}\text { - Too busy with } \\
\text { additional } \\
\text { commitments } \\
\text { at home/work } \\
(n=49) \\
\text { - Work is too } \\
\text { stressful }(n=3)\end{array}$ & $\begin{array}{l}\text { - In too much pain } \\
\text { in general to } \\
\text { complete strategy } \\
(n=12) \\
\text { - Don't complete } \\
\text { strategy if pain is } \\
\text { not present }(n=3)\end{array}$ & $\begin{array}{l}\text { - The strategy takes } \\
\text { too long to do }(n=4) \\
\text { - Not convenient to } \\
\text { complete strategy } \\
\text { every day ( } n=7) \\
\text { - Strategy causes pain } \\
(n=1) \\
\text { - Need additional } \\
\text { equipment to } \\
\text { complete strategy } \\
(n=3)\end{array}$ & $\begin{array}{l}\text { - Need further } \\
\text { advice from } \\
\text { physiotherapist } \\
\text { (unsure what } \\
\text { to do) }(n=2)\end{array}$ & $\begin{array}{l}\text { - } \text { Too tired/lack of } \\
\text { motivation }(n=21) \\
\text { - Forgot }(n=6) \\
\text { - I don't like doing the } \\
\text { strategy }(n=2)\end{array}$ \\
\hline Total: & $n=52,46 \%$ & $n=15,13 \%$ & $n=15,13 \%$ & $n=2,2 \%$ & $n=29,26 \%$ \\
\hline $\begin{array}{l}\text { Enablers } \\
n=172\end{array}$ & $\begin{array}{l}\text { - Need to return } \\
\text { to work/ } \\
\text { activity }(n=5)\end{array}$ & $\begin{array}{l}\text { - Strategy helped } \\
\text { manage long- } \\
\text { term condition- } \\
\text { related symptoms } \\
(n=42) \\
\text { - Strategy helped } \\
\text { prevent further } \\
\text { issues ( } n=2) \\
\text { - Improved sleep } \\
(n=1)\end{array}$ & $\begin{array}{l}\text { - Easy to do the } \\
\text { strategy }(n=54) \\
\text { - Provided instant pain } \\
\text { relief }(n=7) \\
\text { - Convenient, didn't } \\
\text { take much time to } \\
\text { complete }(n=6) \\
\text { - Previous positive } \\
\text { experience of the } \\
\text { strategy }(n=4)\end{array}$ & $\begin{array}{l}\text { Physiotherapist } \\
\text { told me to do it } \\
(n=21)\end{array}$ & $\begin{array}{l}\text { - } \text { Motivated to get better } \\
\text { - Waickly }(n=13) \\
\text { - } \text { treatment an active role in }(n=11) \\
\text { - Strategy was part of my } \\
\text { routine }(n=3) \\
\text { - Sick of being injured } \\
(n=3) \\
\text { - Understand importance } \\
\text { of strategy related to } \\
\text { improving outcomes } \\
(n=1)\end{array}$ \\
\hline Total: & $n=4,2 \%$ & $n=45,26 \%$ & $n=71,41 \%$ & $n=21,12 \%$ & $n=31,18 \%$ \\
\hline
\end{tabular}

strategy which was patient-reported as being completely adhered to ('all') varied from $12 \%$ for advice, $42 \%$ for exercise, and $100 \%$ for removable braces and self-taping (although the last two strategies were infrequently prescribed compared with exercise and advice). Furthermore, only initial short-term adherence (10-14 days) was assessed in our study, subsequent levels of patient adherence could be even lower as adherence has been shown to decline over time (Picorelli, Pereira, Pereira, Felicio, \& Sherrington, 2014). Therefore, physiotherapists should incorporate methods which aid patient adherence to selfmanagement as strategies can only be effective if patients do them.

Social/economic and patient-related factors were the most frequently perceived barriers to adherence

The most frequently described dimensions of adherence-barriers in our study were related to social/economic and patient-related factors such as being too busy or too tired/lack of motivation. This finding supports a number of qualitative studies related to self-management strategies, in particular home-based exercise programmes (Campbell et al., 2001; Medina-Mirapeix, EscolarReina, Gascón-Cánovas, Montilla-Herrador, \& Collins, 2009). It has been reported that when adults perceive their own level of activity as being sufficient, they are less likely to change their behaviour (Visser, Brychta, Chen, \& Koster, 2014). In addition, patients who were poor adherers in earlier research often did not consider that their injury was serious (Bassett, 2015). It may be that patients who reported being too busy or too tired/ lack of motivation to adhere to prescribed self-management strategies were in fact not willing to prioritise their time as they did not feel that it was important to complete their prescribed strategy either due to being sufficiently active (in the case of prescribed exercise) or that their injury was not serious enough to warrant additional self-care.

Condition-related, therapy-related and healthcare team and system-related factors were the most frequently perceived enablers to adherence

The most frequently reported dimension of adherence-enabler was that the strategy helped the patient to manage the symptoms related to their condition, such as improvement in mobility or function (condition-related). Therefore, physiotherapists may be able to aid patient adherence by ensuring that the prescribed self-management strategy is perceived by the patient as having a direct positive effect on their symptoms through the use of appropriate objective 
outcome measures. A recent systematic review reported on 14 different validated measures for assessing the effectiveness of a self-management strategy in patients with chronic pain which included scales on self-efficacy, coping, pain, attitude and activation (Banerjee, Hendrick, Bhattacharjee, \& Blake, 2016). Other dimension-enablers included the relative ease to complete the strategy (therapy-related), which may reflect why some patients reported higher levels of adherence to heat packs and removable braces than exercise. Another enabler was that the physiotherapist told the patient to do it (healthcare team and system-related). A recent qualitative study described some patients as feeling accountable to their physiotherapist and not wanting to let them down, which led to an increase in patient motivation to adhere to their home programme (Hinman, Delany, Campbell, Gale, \& Bennell, 2016). However, this enabler may only improve short-term adherence while patients still have contact with their physiotherapist (Melander Wikman \& Fältholm, 2006). Therefore, whilst acknowledging the influential role the physiotherapist may have in their patient's self-management, it may be more advisable to explore more patient-centred enablers which facilitate the active role and responsibilities of the patient, to effect long-term change in patient adherence behaviour (Kåringen, Dysvik, \& Furnes, 2011). Physiotherapists may play a role in promoting long-term adherence by actively listening to the patient's beliefs about their condition, treatment approaches, and previous experiences with self-management strategies in order that a more tailored and patient-centred strategy is prescribed in the first instance (Peek et al., 2016a). The implementation of peer support groups or follow up phone calls may also encourage patient adherence.

Patients perceived more enablers than barriers to adherence

Patient-reported reasons for their level of adherence to each strategy were more often coded as enablers ( $n=172$ reasons) than barriers ( $n=113$ reasons). The frequency with which enablers were identified may indicate a willingness of patients to become actively involved with their treatment and selfmanagement, which supports earlier results from qualitative studies (Robinson et al., 2014; Stenner, Swinkels, Mitchell, \& Palmer, 2016).

\section{Clinical implications}

Cognitive behavioural theory suggests that there are a range of factors that can affect a patient's adherence-related behaviour, including individual knowledge, attitudes, beliefs, as well as physical and environmental factors (McGrane, Cusack, O'Donoghue, \& Stokes, 2014). There were a number of patientperceived barriers to adherence related to social/economic and patient-related factors such as being too busy or too tired/ lack of motivation. Therefore, before prescribing strategies to their patients, it might be useful for physiotherapists to ask their patients about their ability or intentions to adhere to selfmanagement so that any barriers can be discussed. Techniques such as motivational interviewing should be considered to assess a patient's readiness for change (Barron, Moffett, \& Potter, 2007). Furthermore, patient adherence may be promoted by the belief that the self-management strategy will be effective as well as the belief that the patient is capable of following the requirements of the strategy (Medina-Mirapeix et al., 2009; Picorelli et al., 2014). Therefore, physiotherapists should seek to enable patient adherence through education and enhancing patient self-efficacy (Wesch et al., 2012) via best-practice communication which is purposeful, goal orientated and based on research from empirical studies, practitioner experience and theoretical paradigms (Chan \& Clough, 2010; Hiller, Guillemin, \& Delany, 2015; Isaac \& Franceschi, 2008). One established model of communication is the patient-centred model which emphasises the need to gather information and tailor selfmanagement strategies according to the patient's needs, which may ultimately lead to improved patient outcomes through sustained adherence (Hiller et al., 2015). Physiotherapists should feel assured that time spent designing, prescribing and actively monitoring self-management strategies is time well spent (Novak, 2011).

\section{Limitations}

Given that participants were recruited from just four physiotherapy private practices, results are unlikely to be generalisable to all physiotherapy patients. Nevertheless, the high consent rate achieved (99\%) indicates that results are likely to be representative of patients attending those practices. However, cultural barriers to adherence were not explored in this study as none were reported by the participants, which may be reflective of this particular patient sample and may not be the case if this study were repeated in a different country or geographical location

This study only assessed short-term adherence for patients attending for physiotherapy of musculoskeletal conditions. However, we did not collect data related to specific injury characteristics other than body region. Further studies assessing long-term adherence, and considering self-management of acute compared with chronic conditions, would be a useful addition to the literature. As this study was not powered to examine whether the type of self-management strategy or patient characteristics were associated with the reported barriers and enablers, this remains an area for future research.

\section{CONCLUSION}

Patients reported more enablers than barriers to adherence implying a willingness to play an active role in their selfmanagement programme. The results indicate that adherence may be aided in the following ways: making the strategy less complex, ensuring it does not cause pain, that it is not time consuming, and that it can lead to an improvement in conditionrelated symptoms. It is also recommended that physiotherapists adopt a patient-centred approach to communication using shared decision making when discussing self-management strategies with their patients. The identification of barriers and enablers to physiotherapist-prescribed self-management strategies provides insight into how physiotherapists might manage issues surrounding adherence in the future leading to the optimisation of patient adherence and thus improved treatment outcomes. 


\section{KEY POINTS}

1. Patients $(n=108)$ reported receiving 177 physiotherapistprescribed self-management strategies including exercise, advice and use of heat packs.

2. Patients self-reported being completely adherent to $36 \%$ of prescribed strategies.

3. Patient adherence may be aided by: making the strategy less complex, ensuring it does not cause pain, that it isn't time consuming, and that it can lead to an improvement in condition-related symptoms.

4. Physiotherapists should ask their patients about their ability or intentions to adhere to a prescribed strategy early on during the prescription process so that any barriers to adherence can be discussed and potentially mitigated.

\section{DISCLOSURES}

KP would like to acknowledge the University of Newcastle Postgraduate Research Scholarship-Central 50:50. MC is supported by National Health and Medical Research Council TRIP Fellowship. The authors have no conflicts of interest to declare.

\section{CORRESPONDING AUTHOR}

Kerry Peek, School of Medicine and Public Health, Bowman Building, University of Newcastle, University Drive, Callaghan, NSW, Australia. Telephone: +61 422905 476. Email: Kerry. Peek@uon.edu.au.

\section{REFERENCES}

Alexandre, N. M., Nordin, M., Hiebert, R., \& Campello, M. (2002) Predictors of compliance with short-term treatment among patients with back pain. Revista Panamericana de Salud Pública, 12(2), 86-94 doi:S1020-49892002000800003 [pii]

Banerjee, A., Hendrick, P., Bhattacharjee, P., \& Blake, H. (2016). A systematic review of outcome measures utilised to measure change in selfmanagement in clinical trials in non-cancer chronic pain. Physiotherapy, 102 , e135.

Barron, C. J., Moffett, J. A., \& Potter, M. (2007). Patient expectations of physiotherapy: definitions, concepts, and theories. Physiotherapy Theory \& Practice, 23(1), 37-46.

Bassett, S. F. (2015). Bridging the intention-behaviour gap with behaviour change strategies for physiotherapy rehabilitation non-adherence. New Zealand Journal of Physiotherapy, 43, 105-111 107p. doi:10.15619/ NZJP/43.3.05.

Campbell, R., Evans, M., Tucker, M., Quilty, B., Dieppe, P., \& Donovan, J. L. (2001). Why don't patients do their exercises? Understanding noncompliance with physiotherapy in patients with osteoarthritis of the knee. Journal of Epidemiology and Community Health, 55(2), 132-138.

Chan, S., \& Clough, A. (2010). A critical evaluation of evidence-based practice of physiotherapy in musculoskeletal medicine. International Musculoskeletal Medicine, 32(4), 163-166 164p. doi:10.1179/175361541 OY.0000000006.

DiMatteo, M. R., Haskard-Zolnierek, K. B., \& Martin, L. R. (2012). Improving patient adherence: a three-factor model to guide practice. Health Psychology Review, 6(1), 74-91. doi:10.1080/17437199.2010.537592.
French, S. D., Cameron, M., Walker, B. F., Reggars, J. W., \& Esterman, A. J (2006). A Cochrane review of superficial heat or cold for low back pain. Spine, 31(9), 998-1006. doi:10.1097/01.brs.0000214881.10814.64.

Hendrick, P., Mani, R., Bishop, A., Milosavljevic, S., \& Schneiders, A. G. (2013). Therapist knowledge, adherence and use of low back pain guidelines to inform clinical decisions--a national survey of manipulative and sports physiotherapists in New Zealand. Manual Therapy, 18(2), 136 142.

Hiller, A., Guillemin, M., \& Delany, C. (2015). Exploring healthcare communication models in private physiotherapy practice. Patient Education \& Counselling, 98(10), 1222-1228. doi:10.1016/j. pec.2015.07.029

Hinman, R. S., Delany, C. M., Campbell, P. K., Gale, J., \& Bennell, K. L. (2016). Physical therapists, telephone coaches, and patients with knee osteoarthritis: qualitative study about working together to promote exercise adherence. Physical Therapy, 96(4), 479-493. doi:10.2522/ ptj.2015026.

Isaac, C. A., \& Franceschi, A. (2008). EBM: evidence to practice and practice to evidence. Journal of Evaluation in Clinical Practice, 14(5), 656-659. doi:10.1111/j.1365-2753.2008.01043.x

Jack, K., McLean, S. M., Moffett, J. K., \& Gardiner, E. (2010). Barriers to treatment adherence in physiotherapy outpatient clinics: a systematic review. Manual Therapy, 15(3), 220-228.

Kåringen, I., Dysvik, E., \& Furnes, B. (2011). The elderly stroke patient's long-term adherence to physiotherapy home exercises. Advances in Physiotherapy, 13(4), 145-152.

Kolt, G. S., \& McEvoy, J. F. (2003). Adherence to rehabilitation in patients with low back pain. Manual Therapy, 8(2), 110-116.

Liddle, S. D., Baxter, G. D., \& Gracey, J. H. (2009). Physiotherapists' use of advice and exercise for the management of chronic low back pain: A national survey. Manual Therapy, 14, 189-196.

Lui, K. C., \& Hui, S. S. C. (2009). Participation in and adherence to physical activity in people with physical disability. Hong Kong Journal of Physiotherapy, 27(1), 30-38. doi:10.1016/\$1013-7025(10)70006-3.

Matthews, J., Hall, A. M., Hernon, M., Murray, A., Jackson, B., Taylor, I., Hurley, D. A. (2015). A brief report on the development of a theoretically-grounded intervention to promote patient autonomy and self-management of physiotherapy patients: face validity and feasibility of implementation. BMC Health Services Research, 15(1), 260.

McArthur, D., Dumas, A., Woodend, K., Beach, S., \& Stacey, D. (2014). Factors influencing adherence to regular exercise in middle-aged women: a qualitative study to inform clinical practice. BMC women's health, 14(1), 1.

McGrane, N., Cusack, T., O'Donoghue, G., \& Stokes, E. (2014). Motivational strategies for physiotherapists. Physical Therapy Reviews, 19(2), 136-142. doi:10.1179/1743288X13Y.0000000117.

Medina-Mirapeix, F., Escolar-Reina, P., Gascón-Cánovas, J. J., MontillaHerrador, J., \& Collins, S. M. (2009). Personal characteristics influencing patients' adherence to home exercise during chronic pain: a qualitative study. Journal of Rehabilitation Medicine, 41(5), 347-352. doi:10.2340/16501977-0338.

Melander Wikman, A., \& Fältholm, Y. (2006). Patient empowerment in rehabilitation: "Somebody told me to get rehabilitated". Advances in Physiotherapy, 8(1), 23-32.

Novak, I. (2011). Effective home programmeme intervention for adults: a systematic review. Clinical Rehabilitation, 25(12), 1066-1085 1020p. doi:10.1177/0269215511410727.

O'Brien, L. (2010). Adherence to therapeutic splint wear in adults with acute upper limb injuries: a systematic review. Journal of Hand Therapy, 15(1), 3-12 
Page, C. J., Hinman, R. S., \& Bennell, K. L. (2011). Physiotherapy management of knee osteoarthritis. International Journal of Rheumatic Diseases, 14(2), 145-151.

Peek, K., Carey, M., Sanson-Fisher, R., \& Mackenzie, L. (2017). Physiotherapists' perceptions of patient adherence to prescribed self-management strategies: a cross-sectional survey of Australian physiotherapists. Disability and Rehabilitation, Sep;39(19):1932-1938. doi: 10.1080/09638288.2016.1212281.

Peek, K., Sanson-Fisher, R., Mackenzie, L., \& Carey, M. (2015). Patient adherence to physiotherapist prescribed self-management strategies: A critical review. International Journal of Therapy \& Rehabilitation, 22(11), 535-543

Peek, K., Sanson-Fisher, R., Mackenzie, L., \& Carey, M. (2016). Interventions to aid patient adherence to physiotherapist prescribed self-management strategies: A systematic review. Physiotherapy, 102(2), 127-135. doi:10.1016/j.physio.2015.10.003.

Peek, K., Carey, M., Sanson-Fisher, R., \& Mackenzie, L. (2016a). Aiding patient adherence to physiotherapist-prescribed self-management strategies: An evidence-based behavioural model in practice. Physical Therapy Reviews. 21(2), 124-130.doi:10.1080/10833196.2016.1226537.

Pisters, M. D., Veenhof, C., Schellevis, F. G., Twisk, J. W., Dekker, J., \& De Bakker, D. H. (2010). Exercise adherence improving long-term patient outcome in patients with osteoarthritis of the hip and/or knee. Arthritis Care \& Research, 62(8), 1087-1094.

Pisters, M. D., Veenhof, C., de Bakker, D.H., Schellevis, F.G., Dekker, J. (2010a). Behavioural graded activity results in better exercise adherence and more physical activity than usual care in people with osteoarthritis. Journal of Physiotherapy, 56, 41-47

Picorelli, A. M., Pereira, L. S., Pereira, D. S., Felicio, D., \& Sherrington, C. (2014). Adherence to exercise programmes for older people is influenced by programme characteristics and personal factors: a systematic review. Journal of Physiotherapy, 60(3), 151-156. doi:10.1016/j. jphys.2014.06.012.
Potter, W. J., \& Levine-Donnerstein, D. (1999). Rethinking validity and reliability in content analysis. Journal of Applied Communication Research, 27(3), 258-284. doi:10.1080/00909889909365539

Robinson, L., Newton, J. L., Jones, D., \& Dawson, P. (2014). Self-management and adherence with exercise-based falls prevention programmemes: a qualitative study to explore the views and experiences of older people and physiotherapists. Disability \& Rehabilitation, 36(5), 379-386. doi:10.3109/0 9638288.2013 .797507$.

Sabaté, E. (2003). Adherence to long-term therapies: evidence for action. World Health Organization. Retrieved from http://www.who.int/chp/ knowledge/publications/adherence_report/en/

Schneiders, A. G., Zusman, M., \& Singer, K. P. (1998). Exercise therapy compliance in acute low back pain patients. Manual Therapy, 3(3), 147 152.

Stenner, R., Swinkels, A., Mitchell, T., \& Palmer, S. (2016). Exercise prescription for non-specific chronic low back pain (NSCLBP): a qualitative study of patients' experiences of involvement in decision making. Physiotherapy, 102(4):339-344. doi:10.1016/j.physio.2015.08.005.

Visser, M., Brychta, R. J., Chen, K. Y., \& Koster, A. (2014). Self-reported adherence to the physical activity recommendation and determinants of misperception in older adults. Journal of Aging \& Physical Activity, 22(2), 226-234. doi:10.1123/japa.2012-0219.

Wesch, N., Hall, C., Prapavessis, H., Maddison, R., Bassett, S., Foley, L., Brooks, S., Forwell, L. (2012). Self-efficacy, imagery use, and adherence during injury rehabilitation. Scandinavian Journal of Medicine \& Science in Sports, 22(5), 695-703. 